\title{
Designing Automated Vehicle Location Systems for Archived Data Analysis
}

\author{
Peter G. Furth, Theo H. J. Muller, James G. Strathman, and Brendon Hemily
}

\begin{abstract}
Automatic vehicle location (AVL) and other automated data collection systems can provide a rich and extensive database that can be analyzed to improve transit management and performance. In the past, many such systems have failed to provide a good data archive, while others have had success. Through the use of an extensive survey and in-depth case studies of nine transit agencies, the key issues in system design that help determine whether a data collection system will provide the useful data archive that many agencies desire are examined. In issues related to design of the data collection system itself, the focus is on five different levels of spatial detail. Issues related to database design are also discussed, as are organizational issues.
\end{abstract}

Imagine a transit agency with an automatic vehicle location (AVL) system in which buses radio in their location every minute; at the control center, service managers can see in real time how far off schedule each bus is. But this AVL system doesn't store data in a way that makes it possible to query historic data, so when management wants to know on-time performance or the running time distribution on a particular route, checkers must go out into the field. So, although an automated system is collecting data 365 days a year, management decisions are being made on the basis of meager manual samples.

This situation, unfortunately common to many U.S. cities (I), underscores the point made by Kemp (2) that off-line analysis of historic data places different demands on data systems than real-time applications. Thanks to the ongoing technology boom, automated data-gathering systems on buses are proliferating. However, their design has been dominated mostly by real-time applications such as computer-aided dispatching, "next stop" announcements, and "next arrival" displays. Technologically, those systems can be made capable of producing a rich and immense database on operations and passenger activity that can be analyzed off-line. However, that promise has often gone unfulfilled because planning and design for the system failed to include key features that facilitate the capture, archival, and analysis of operations data. A classic example is an AVL system that didn't archive data at all until a creative service analyst discovered that the AVL messages were being written to a temporary database (meant for diagnostic purposes) that was overwritten every

P. G. Furth, Department of Civil and Environmental Engineering, 400 SN, 360 Huntington Avenue, Northeastern University, Boston, MA 02115. T. H. J. Muller, Department of Civil Engineering and the Geosciences, Delft University of Technology, P.O. Box 5048, 2600 GA Delft, Netherlands. J. G. Strathman, Center for Urban Studies, Portland State University, Room URBN 350-C, P.O. Box 751CUS, Portland, OR 97207. B. Hemily, 107 Chester Avenue, Toronto, Ontario M4K 2Z8, Canada.

Transportation Research Record: Journal of the Transportation Research Board, No. 1887, TRB, National Research Council, Washington, D.C., 2004, pp. 62-70.
$2 \mathrm{~min}$. He wrote a program that copies the contents of the temporary database every $2 \mathrm{~min}$ to a permanent database from which trip trajectories could be reproduced (3).

Fortunately, in some cities, data archiving has been designed into the system; every day's data are archived in a convenient format and analyzed regularly to improve schedules, planning, and control policy and otherwise support a host of management functions. The goal was to identify and examine the key issues that enable an automatic data collection system to fulfill the promise of a rich archive of operations and passenger activity data that can be fruitfully used to improve transit performance and management by studying these successes-as well as some failures.

This paper begins with two sections that summarize of the state of practice based on a broad scan of the industry and case studies of nine transit agencies. Then, it addresses the most critical issue identified in this survey: the level of geographic detail of automatically collected data, which are presented in a hierarchy from eventindependent, random-location records to records that offer detail about timepoints, stops, and events between stops. A brief section summarizes current and potential uses of archived AVL and automatic passenger counter (APC) data, and finds that the more detailed levels of data are more valuable. The following three sections discuss system design issues, database design issues, and organizational issues that affect the ability of AVL and APC systems to deliver useful data and data analyses.

\section{SURVEY OF PRACTICE}

In 2001, the Transit Cooperative Research Program contracted with Northeastern University for Project $\mathrm{H}-28$, Uses of Archived AVL-APC Data to Improve Transit Performance and Management. This paper is based on Phase I of that project, which concluded with an interim report (4). To survey the state of practice, that project included

- A literature search and mail survey that gathered information on AVL and APC systems (planned as well as used) at 122 U.S., 14 Canadian, and 26 European transit agencies;

- Telephone interviews with 20 U.S. and 14 Canadian agencies;

- Case studies, which have been published by Furth et al. (4), of 9 transportation agencies (5 American, 2 Canadian, and 2 Dutch); and

- A day-long workshop attended by representatives of 9 vendors, 8 transit agencies, and several consultants and researchers.

The survey focused on which data were captured, how data capture related to system design, how data were archived and analyzed, and in what functions the data were used. The case studies were particularly informative. Objectives, constraints, practices, and experience 
vary so widely around this topic that it is hard to design a survey that will capture the relevant information.

\section{ONBOARD TECHNOLOGIES}

For many years, the only kinds of automated data collection systems providing both time- and location-stamped data were AVL and APC systems. They were generally stand-alone systems, each with its own location and (if available) schedule referencing system. Traditionally, AVL meant data being sent over the air through the radio system, and APC meant data being stored on board and uploaded at the end of the day. More recently, some AVL systems have begun to provide onboard data storage, and other types of automated systems have appeared that can provide much of the same kind of operations data as traditional APC and AVL systems. For example,

- Event recorder. It can be thought of as an AVL without the radio or an APC without a passenger counter. Events such as door opening and closing are recorded in an onboard computer for later analysis. The function and benefits of the event recorder system used by the Hermes agency in Eindhoven, the Netherlands, have been examined $(4,5)$.

- Stop announcement system. This kind of system requires a bus to know which stop it is about to serve. If the system also makes a record of the arrival and departure at each stop, it doubles as an event recorder. Installation of such a system is under way at the Chicago Transit Authority (CTA; Chicago, Illinois).

- Fare collection equipment. The latest generation of fareboxes makes time-stamped records of each transaction. To date, none has been integrated with a location system, but it is certainly technologically feasible for a system to make transaction records stamped with both time and location information. Although fare transaction records don't indicate where people exit and therefore don't permit exact knowledge of passenger load, algorithms have been developed to estimate load on the basis of historic boarding counts in the reverse direction (6). Fare media that include passenger identification permit the estimation of not only alighting location but also linked trips and transfers from information including the passenger's earlier and subsequent boarding locations and elapsed time (7). Metro Transit (Minneapolis, Minnesota) plans to integrate such a system (based on smart cards) in 2004. As fare transaction records become a more important source of operations data, they may dampen demand for passenger counters.

As intelligent devices are integrated on board, the distinction between system types (AVL, APC, or event recorder) breaks down. Many recent installations use the "smart bus" design in which a primary onboard computer tracks location, usually using global positioning, so that devices such as passenger counters do not need their own location-tracking ability. The function of such a system depends on which devices are attached to the onboard computer, which usually serves as event recorder.

The systems of the case study sites are illustrative examples. i.

- The Tri-Met (Portland, Oregon) system features AVL, APC, and event recording. Its onboard computer, supplied by the AVL fendor, writes an event at each stop that includes stop information, slongitude, latitude, door open moment, dwell (i.e., door open) duration, moment of exiting a $30-\mathrm{m}$ radius around the stop, indicators of door opening and lift use, and maximum speed since the previous stop. More than one-half of the buses have passenger counters; their stop records also include on-and-off counts. Location and status are radioed to the control center on an exception basis (i.e., when more than a predetermined deviation from schedule or when off route). Operator-initiated coded radio messages (e.g., "road blocked by train," "pass-up") are recorded in the onboard computer with time and location stamps. The onboard computer is also connected to a traffic signal priority request emitter, triggered only when the bus is behind schedule.

- A stop announcement system currently being installed at the CTA features event recording on all buses. On buses with passenger counters ( $15 \%$ of the fleet), stop event records will include onand-off counts. At the same time, an independent 1995-vintage AVL system sends radio messages every 40 to $70 \mathrm{~s}$. Unfortunately, this data stream is not suitable for routine operations analysis.

- At New Jersey Transit (NJ Transit; Newark, New Jersey), an AVL vendor supplied the onboard computer with location tracking function, even though NJ Transit's system is not connected to a radio. It features event recording with passenger counts and was designed to be later integrated with the radio and other devices through a J1708 network.

- At Metro Transit, the AVL vendor supplied the onboard computer, which is connected to passenger counters (on $12 \%$ of the fleet) and the radio. The radio carries both round robin polling data (bus location when polled) and event messages, including timepoint messages. Stop messages are sent only by buses with passenger counters and only if the buses actually stop. During periods of radio failure, event messages are recorded on board, uploaded at the end of the day, and inserted into the radio message database. The round robin polling data are saved only for incident investigation and are not prepared for routine off-line analysis.

- OC Transpo (Ottawa, Ontario, Canada) and Société de Transport de Montréal (STM; Montreal, Quebec, Canada) have standalone APCs. King County Metro (Seattle, Washington) has both AVL and APC systems that share log-in information and signposts but are otherwise independent. The AVL system sends timepoint messages as well as performing round robin polling; like Metro Transit, only the timepoint event messages are used for routine off-line analysis.

- The Haagsche Tramweg Maatschappij (HTM; The Hague, the Netherlands) system is like Tri-Met's, featuring onboard event recording at every stop, passenger counts on a fraction of the fleet (in this case, about $25 \%$ ), radio transmission of real-time location to central control, and traffic signal priority requests.

\section{LEVELS OF SPATIAL DETAIL}

The most essential issue affecting the usefulness of an automated data collection system for off-line analysis is what data it captures. This research identified a hierarchy of levels of location detail, with five levels labeled $\mathrm{A}-\mathrm{E}$ in order of increasing value and detail.

\section{Level A: Round Robin Polling Data}

Level A, the least level of detail, consists of round robin polling, the most common approach to AVL. Vehicles report their location at the moment they are polled, rather than at specific locations of interest; therefore, Level A data can be called location-at-time data. The typical polling interval is 40 to $120 \mathrm{~s}$. 


\section{Level B: Timepoint Records}

Level B consists of timepoint records, which, unlike Level A, contain time-at-location information. To create timepoint records, the bus has to know when it leaves a timepoint. In newer AVL systems, it is done by putting intelligence on the bus; the onboard computer tracks location against a base map. King County Metro devised a clever way to get timepoint records from its older AVL system in which the central computer tracks vehicle location using signpost and odometer data received from buses. About $3 \mathrm{~min}$ of travel time before a timepoint, the central computer calculates and transmits to the bus the expected odometer reading at the next timepoint; when the odometer reaches that value, the bus records time and location and transmits a timepoint message.

\section{Level C: Stop Records}

Stop records are characteristic of APC and stop announcement systems but also can be made by AVL systems (without passenger counts). Systems that create stop records often include door sensors and therefore measure the times at which doors open and close. OC Transpo's APC stop records include, along with passenger counts, stop time (using odometer pulses to detect when the wheels stop and start again) and dwell time (from door opening to the last passenger detection).

\section{Level D: Segment Performance Summary Added to Stop Record}

Level D complements Level $\mathrm{C}$ by adding summary information about bus performance between stops. Because the segment information is summarized, this level of data lends itself to the same database structure as Level $\mathrm{C}$, with one record per stop module that includes a stop and the segment preceding it. At Hermes and HTM, the onboard computer notes the time at which bus speed crosses a threshold crawl speed (say, $5 \mathrm{~km} / \mathrm{h}$ ) and accumulates time occurring below crawl speed; the accumulated value is saved as segment delay time. Tri-Met records the maximum speed the bus attained on each segment.

\section{Level E: Detailed Event Data}

In the finest level of detail, a host of operation events are recorded. A record might be made for each door opening and closing, for crossing a crawl speed threshold or a high speed threshold, or for a heading change, as at NJ Transit. Some systems designed mainly for Level C or Level $\mathrm{D}$ data also have a learning mode that records position and heading every few seconds.

\section{USES OF ARCHIVED DATA}

The analyses and tools that might use data related to archived location are listed in Table 1. For each analysis or tool shown, the table indicates the level of spatial detail needed, the extent to which the tool is already in use, and the nonstandard data items that must also be captured. Space limitations forbid a discussion of each item; however, key items are discussed in the following section as they affect system design.
One of the key findings of this summary is the small number of analyses that can be done using Level A spatial detail and the small number requiring Level $\mathrm{E}$ detail. Most analyses require Level B (timepoint) or Level C (stop) data; the more complex the analysis, the greater the need for detail Levels $C$ and $D$.

\section{SYSTEM DESIGN ISSUES}

\section{Level of Spatial Detail Issues}

\section{Time-at-Location or Location-at-Time?}

Location-at-time (Level A) data are fine for locating a bus in real time during an emergency; for analysis of historic data, however, they are clearly inferior to stop and timepoint records. Measuring running time and schedule adherence requires knowledge of departure time from timepoints. Polling data therefore introduces interpolation error, whose magnitude depends on the polling interval. More serious, though, is the problem of imprecise matching, particularly in periods of traffic congestion, when it can be difficult to distinguish whether a bus is reporting coordinates close to those of a stop, is in a queue waiting to reach the stop, is at the stop with its doors open, or has left the stop and is waiting in a traffic queue.

This survey did not find any transit agency routinely using Level A data for operation analyses. Researchers used such a data stream from Ann Arbor, Michigan, for some operational analyses (8), but the process of going from raw poll messages to trajectories matched to route and schedule was too involved to become routine. As mentioned, the three case study agencies with round robin polling data do not use it off-line except for incident investigation using playback. King County Metro's AVL enhancement to enable Level B data has been enthusiastically received by staff members in scheduling and in service analysis who use the timepoint data to analyze running time and on-time performance. Also, these surveys indicate that all of the traditional AVL suppliers, even if they still use polling to support real-time applications, include timepoint records in their data streams as well.

However, a relatively new entry to the market is stand-alone "next arrival" systems that track bus location using polling. Like earlier AVL systems, they are designed around a real-time application, and according to the vendor interviewed, they use polling data because it minimizes the amount of equipment installed in the vehicles, making the system less expensive. This vendor claims to have obtained good test results using the data stream for off-line analysis of on-time performance. The data stream includes predicted arrival time (based on the vendor's proprietary algorithms), and it stands to reason that as buses get closer to a stop, predicted arrival time should become rather accurate, especially if the polling cycle is short, because predicting arrival time is their core business. However, given the limitations of the data stream, some interpolation (or, in this case, extrapolation) error is bound to persist, and identifying arrival or departure time when traffic congestion can slow service to a crawl near bus stops is likely to remain a problem.

Time- and distance-based records can be useful as a supplement to stop-level records to help understand what is going on between stops when the time between stops is large. For example, OC Transpo logs an "idle time" event when a bus has not moved for $45 \mathrm{~s}$; it helps identify points of serious traffic delay and gives positive information about layover processes. At King County Metro, to help track buses on express routes, an APC record is written if the 
TABLE 1 Decision Support Tools and Analyses and Their Data Needs

\begin{tabular}{|c|c|c|c|c|}
\hline Function & $\begin{array}{l}\text { TooVAnalysis and [Usage } \\
\text { Code*] }\end{array}$ & $\begin{array}{l}\text { Detail Level } \\
\text { Needed }\end{array}$ & Additional Items Needed & External Data Needed \\
\hline $\begin{array}{l}\text { General service monitoring, } \\
\text { including contract } \\
\text { compliance }\end{array}$ & $\begin{array}{l}\text { - Missed trips [1] } \\
\text { - Schedule adherence [4] }\end{array}$ & $A$ or $B$ & Incident codes, control messages & Schedule \\
\hline \multirow{3}{*}{$\begin{array}{l}\text { Targeted Investigations } \\
\text { - } \quad \begin{array}{l}\text { Customer service } \\
\text { (complaints) }\end{array} \\
\text { - } \quad \begin{array}{l}\text { Security/legal } \\
\text { (incidents, accidents) }\end{array} \\
\text { - Operator performance }\end{array}$} & $\begin{array}{l}\text { Trip investigation at gross level } \\
\text { (was it there? was it off route?) [4] }\end{array}$ & A & Off route, incident codes, control messages & Schedule, payroll \\
\hline & $\begin{array}{l}\text { Trip investigation: early, late, } \\
\text { overcrowded? [3] }\end{array}$ & $\mathrm{C}$ & & \\
\hline & $\begin{array}{l}\text { Trip investigation: speed, } \\
\text { acceleration [2] }\end{array}$ & $D$ or $E$ & $\begin{array}{l}\text { Maximum speed; records every } 2 \text { s or more } \\
\text { to measure accel., decel. rates; GPS altitude }\end{array}$ & \\
\hline \multirow[t]{8}{*}{$\begin{array}{l}\text { Scheduling and Monitoring } \\
\text { Running Time }\end{array}$} & $\begin{array}{l}\text { Route and segment running time } \\
\text { analysis (mean and distribution) [4] }\end{array}$ & B & & \\
\hline & $\begin{array}{l}\text { Suggesting running time based on } \\
\text { percentiles [3] }\end{array}$ & B & & \\
\hline & $\begin{array}{l}\text { Selecting homogeneous running } \\
\text { time periods [3] }\end{array}$ & B & & \\
\hline & $\begin{array}{l}\text { Suggesting half-cycle time based } \\
\text { on percentiles [2] }\end{array}$ & B & & \\
\hline & $\begin{array}{l}\text { Running time analysis net of } \\
\text { holding time [2] }\end{array}$ & C & Incident codes, control messages & Schedule \\
\hline & Speed and traffic delay [2] & $\mathrm{D}$ & & Schedule \\
\hline & Unsafe operations monitoring [0] & Dor $E$ & $\begin{array}{l}\text { Maximum speed; records every } 2 \text { s or more } \\
\text { to measure accel., decel. rates }\end{array}$ & \\
\hline & $\begin{array}{l}\text { Relating running time to weather, } \\
\text { roadway incidents, and special } \\
\text { events [1] }\end{array}$ & B & & $\begin{array}{l}\text { Weather, roadway incident } \\
\text { data, special event data }\end{array}$ \\
\hline \multirow{5}{*}{$\begin{array}{l}\text { Schedule Adherence and } \\
\text { Connection Protection } \\
\text { (service and operational } \\
\text { quality) }\end{array}$} & Percent early, late by location [4] & $\begin{array}{l}\text { B (timepoint- } \\
\text { level) or C (stop } \\
\text { level) }\end{array}$ & & Schedule \\
\hline & $\begin{array}{l}\text { Distribution of schedule deviation at } \\
\text { a timepoint [3] }\end{array}$ & $\mathrm{B}$ or $\mathrm{C}$ & & \\
\hline & $\begin{array}{l}\text { Graphical display of schedule } \\
\text { deviation distribution along a route } \\
\text { [2] }\end{array}$ & $\mathrm{B}$ or $\mathrm{C}$ & & \\
\hline & $\begin{array}{l}\text { Experienced lateness and earliness } \\
{[1]}\end{array}$ & C & & $\begin{array}{l}\text { Farebox transactions with } \\
\text { linked trip data }\end{array}$ \\
\hline & Connection protection [1] & C & Control messages & $\begin{array}{l}\text { Farebox transactions with } \\
\text { linked trip data }\end{array}$ \\
\hline \multirow[t]{3}{*}{$\begin{array}{l}\text { Headway Analysis } \\
\text { (service and operational } \\
\text { quality) }\end{array}$} & $\begin{array}{l}\text { Headway deviations (mean and } \\
\text { distribution by timepoint) [3] }\end{array}$ & $\begin{array}{l}\text { B (timepoint- } \\
\text { level) or C (stop } \\
\text { level); all buses } \\
\text { reporting }\end{array}$ & Incident codes, control messages & Schedule \\
\hline & $\begin{array}{l}\text { Impact of headway variability on } \\
\text { passenger waiting time for random } \\
\text { passenger arrivals [1] }\end{array}$ & C & Incident codes & Farebox \\
\hline & $\begin{array}{l}\text { Plot successive trajectories } \\
\text { (bunching analysis) [2] }\end{array}$ & C & incident codes, control messages & Schedule \\
\hline \multirow[t]{6}{*}{ Demand Analysis } & $\begin{array}{l}\text { Load profile (mean ons, offs, and } \\
\text { load by stop along a route; also } \\
\text { passenger-miles) [4] }\end{array}$ & C & & \\
\hline & Load variations [3] & C & & \\
\hline & $\begin{array}{l}\text { Analysis of trip maximum loads and } \\
\text { maximum load points [1] }\end{array}$ & C & & \\
\hline & $\begin{array}{l}\text { Time-dependent demand and load } \\
\text { analysis, and suggesting trip start } \\
\text { times to achieve load targets [1] }\end{array}$ & C & & \\
\hline & $\begin{array}{l}\text { Analyze overload, lift, bicycle, and } \\
\text { other events by stop and time [3] }\end{array}$ & C & Incident codes & \\
\hline & Transfer and linked trip analysis [1] & C & Farebox transactions with card IDs & Farebox \\
\hline
\end{tabular}

NotE: Italics indicate optional items or data. GPS $=$ Global Positioning System. GIS = geographic information system.

*Usage codes: 4 = used commonly by agencies with AVL-APC data; $3=$ used by some agencies with AVL-APC data; 2 = used by only a few agencies with AVLAPC data; $1=$ used experimentally or ad hoc; $0=$ not used. 
TABLE 1 (continued) Decision Support Tools and Analyses and Their Data Needs

\begin{tabular}{|c|c|c|c|c|}
\hline Function & $\begin{array}{l}\text { ToovAnalysis and [Usage } \\
\text { Code"] }\end{array}$ & $\begin{array}{l}\text { Detail Level } \\
\text { Needed }\end{array}$ & Additional Items Needed & External Data Needed \\
\hline \multirow[t]{5}{*}{$\begin{array}{l}\text { Geographic and Planning } \\
\text { Analysis }\end{array}$} & $\begin{array}{l}\text { Geocoding stops and other points } \\
\text { of interest [2] }\end{array}$ & $\mathrm{C}$ & & GIS \\
\hline & $\begin{array}{l}\text { Mapping bus path through } \\
\text { shopping centers, new } \\
\text { subdivisions, etc. [3] }\end{array}$ & $\mathrm{E}$ & & \\
\hline & $\begin{array}{l}\text { Comparing measured vs. nominal } \\
\text { stop locations [1] }\end{array}$ & $\mathrm{C}$ & & \\
\hline & $\begin{array}{l}\text { Relate on and off data to demand } \\
\text { rates in traffic analysis zones and to } \\
\text { geographic database [1] }\end{array}$ & C & & $\begin{array}{l}\text { GIS, regional travel demand } \\
\text { model database }\end{array}$ \\
\hline & $\begin{array}{l}\text { Relate service quality data to } \\
\text { geographic database [1] }\end{array}$ & $B$ or $C$ & & GIS, schedule \\
\hline Utilities & Monitoring system failures [4] & A & System diagnostics & \\
\hline \multirow[t]{5}{*}{ Other Operations Analysis } & $\begin{array}{l}\text { Operator performance (schedule } \\
\text { adherence, on-time start, running } \\
\text { time, headway maintenance) [1] }\end{array}$ & $\begin{array}{l}\text { B (timepoint level) } \\
\text { or C (stop level) }\end{array}$ & Incident codes, control messages & Schedule, farebox data \\
\hline & Dwell time analysis [2] & C & $\begin{array}{l}\text { Passenger entry-exit moment, farebox } \\
\text { transactions, incident codes }\end{array}$ & \\
\hline & $\begin{array}{l}\text { Layover and pull-in/pull-out } \\
\text { analysis [0] }\end{array}$ & B & Incident codes, control messages, off route & Schedule \\
\hline & $\begin{array}{l}\text { Control effectiveness: any service } \\
\text { quality monitoring or service } \\
\text { analysis, related to control } \\
\text { messages }\end{array}$ & $\begin{array}{l}\text { As required for } \\
\text { each analysis }\end{array}$ & Incident codes and control messages & \\
\hline & $\begin{array}{l}\text { - Before/after study } \\
\text { - Special event/weather } \\
\text { analysis } \\
\end{array}$ & $\begin{array}{l}\text { As required by } \\
\text { the type of } \\
\text { analysis }\end{array}$ & As required by the type of analysis & $\begin{array}{l}\text { As required by the type of } \\
\text { analysis }\end{array}$ \\
\hline \multirow[t]{2}{*}{$\begin{array}{l}\text { Passenger Information } \\
\text { Monitoring }\end{array}$} & $\begin{array}{l}\text { Prediction accuracy (match } \\
\text { announced stop or predicted arrival } \\
\text { time with actual) [1] }\end{array}$ & C & Annunciator & Schedule, GIS \\
\hline & $\begin{array}{l}\text { Accuracy of route data in } \\
\text { destination sign and farebox [0] }\end{array}$ & A & Destination sign, farebox & Schedule \\
\hline \multirow[t]{2}{*}{ Payroll } & Verify sign-in data [2] & A & & Schedule, payroll \\
\hline & $\begin{array}{l}\text { Examine operator's duty when } \\
\text { there's an overtime claim [2] }\end{array}$ & A & Off route, incident codes, control messages & Schedule, payroll \\
\hline \multirow[t]{3}{*}{ Maintenance Management } & Analyze maintenance incidents [0] & D & $\begin{array}{l}\text { Incident codes, control messages, on and off } \\
\text { counts, GPS altitude, vehicle health } \\
\text { indicators }\end{array}$ & Maintenance, altitude \\
\hline & Monitoring vehicle demands [0] & $\mathrm{D}$ & $\begin{array}{l}\text { On-off counts, GPS altitude, vehicle health } \\
\text { indicators }\end{array}$ & Maintenance, GIS \\
\hline & Analyze failure trends [0] & D & $\begin{array}{l}\text { Incident codes, control messages, on and off } \\
\text { counts, GPS altitude, vehicle health } \\
\text { indicators }\end{array}$ & Maintenance, GIS \\
\hline Strategic Planning & Trends analysis [2] & $\begin{array}{l}\text { As required by } \\
\text { the type of } \\
\text { analysis }\end{array}$ & As required by the type of analysis & $\begin{array}{l}\text { As required by the type of } \\
\text { analysis }\end{array}$ \\
\hline
\end{tabular}

NOTE: Italics indicate optional items or data. GPS = Global Positioning System. GIS = geographic information system .

"Usage codes: 4 = used commonly by agencies with AVL-APC data; 3 = used by some agencies with AVL-APC data; 2 = used by only a few agencies with AVLAPC data; 1 = used experimentally or ad hoc; $0=$ not used.

bus has gone a mile without making any other type of record. Many systems also include "heartbeat" records that help confirm whether the system is working.

\section{Timepoint or Stop-Level Data?}

Stop-level data are needed for passenger counts, of course; but for operation data (arrival and departure times), what incremental value is to be gained from getting data at all stops as well as at timepoints? Because scheduling practice in the United States is based on timepoints, only timepoint data are needed for basic running time and schedule adherence analysis. Metro Transit's system design emphasizes this distinction: On buses with APCs, stop records are created, and on buses with only AVLs, only timepoint records are created. Interestingly, this issue does not arise in the Netherlands because every stop is a timepoint.

Timepoint data tend to be favored by systems that rely primarily on radio transmission for data recording because they do not consume much radio channel capacity; timepoint messages are not very frequent and tend to be rather short, including only timepoint identification, time and location stamp, and identifiers.

The following analyses that would benefit from stop-level data, even without passenger counts, were identified.

- Investigating complaints about early or late buses. With timepoint data only; one must interpolate between straddling timepoints to verify an early- or late-bus complaint. 
- Bunching analysis. A plot of the trajectories of successive buses can help illustrate and elucidate the bunching process that often affects high-frequency routes. The timepoint level is too coarse for such an analysis.

- Connection protection and travel time. Because stop-level data generally indicate both arrival and departure time (when doors open and close) but timepoint data generally provide only one or the other (usually departure time), stop-level data are better for analyzing whether connections were successfully made and for estimating passenger travel time.

- Net running time. If operators hold at stops to avoid running early, observed running time will be biased by the current schedule. For scheduling, then, one would like to analyze running time net of holding time, as is done at Hermes and HTM. Stop-level observations are used to help identify holding time, as either excessive dwell time (for a bus that is running early and isn't operating its lift) or idle time (at a stop with the doors closed). Another running time analysis used at Hermes and HTM nets out dwell time to separate the impact of ambient traffic on dwell time from the effect of greater passenger demand.

- Headway-load analysis. When a bus is overloaded, analysts have learned to examine the headway: Was the overload due to insufficient service frequency (a planning problem) or irregular headways (a control problem)? Tri-Met reports what fraction of overloads occurred on trips in which measured headway was $50 \%$ above the scheduled headway. Knowing a trip's headway requires departure time data from that trip and its leader, emphasizing the need for stop-level records on the entire fleet, even if only a fraction have passenger counters. Another analysis requiring measured headways, done at both Metro Transit and Tri-Met, is to estimate peak point volume by minute so that scheduled departure times can be adjusted to better balance loads. The general logic is to allocate measured demand over each minute of the measured headway and average over several days' observations. Because peak loads often occur at stops that are not timepoints and because headways vary from stop to stop, stop-level headway data are preferred for such an analysis.

- Predicting arrival time. As transit agencies try to better serve their customers, many are beginning to offer systems that predict arrival time. Such predictions, whether using fixed kiosks or distributed via the Internet or cell phones, must be stop based. Making such predictions accurately requires measuring arrival and departure time at stops.

This final application is one of several that is moving the industry in the direction of stop-level scheduling. Closely related to realtime arrival prediction is the more fundamental question: When is a bus scheduled to depart from a stop? This information is needed for posting schedules at stops and for driving trip-planning applications, both valuable ways of offering information to customers. Two applications that require stop-level schedules and are becoming more prevalent are conditional priority at traffic signals, in which only buses that are behind schedule request priority, and displaying realtime schedule deviation to operators. Currently, Tri-Met, which runs all of these applications, uses stop-level schedules that are simply interpolated between timepoints. Stop-level data offer the potential to generate more accurate stop-level schedules for such applications.

\section{Between-Stop Summary or Detail?}

Collecting a record of detailed events occurring on segments between stops (Level E data) allows a transit agency to create sum- mary measures after the fact from raw data, modifying summary measures as research or experience suggests or as needs dictate. Level D, in contrast, offers only the particular summary measures the system is wired and programmed to provide and is probably adequate if the transit agency knows in advance the summary measures it will want, such as maximum speed or time spent below a crawl speed threshold. Level $\mathrm{E}$ detail is most likely to benefit an agency that is interested in exploring ways to make use of the greater detail it provides. Detailed event data can be useful for improving algorithms for matching and summarizing data. For instance, a record of every time bus speed crosses a crawl speed threshold may help resolve situations such as when a bus stops twice at the same stop, jockeys around at a layover, or holds away from a stop (to avoid running early). NJ Transit is interested in using its Level $E$ data for improving maintenance management by correlating operations measures with maintenance needs, particularly if future generations of its data collection system enable it to integrate data from the vehicle drivetrain system.

\section{Learning Mode}

Learning mode, a limited form of Level $\mathrm{E}$ data, is useful for a transit agency to better map its stops and routes-particularly routes through a shopping center whose "roadways" may not be well mapped. It is also a valuable diagnostic tool that may be used, for example, to examine a route segment that is believed to be suffering Global Positioning System (GPS) signal distortion.

\section{Sampling Issues}

\section{What Fraction of the Fleet to Equip?}

Although real-time applications generally require fleetwide installation for AVL and stop announcement systems, systems meant for offline analysis - mainly APCs - are typically installed on only a subset (typically $10 \%$ to $15 \%$ ) of the fleet. Is this the right percentage?

The average sampling rate is the product of the fleet penetration and data recovery rates. For example, if $10 \%$ of the fleet is equipped and data are recovered from $70 \%$ of their trips, then scheduled trips will be observed, on average, $7 \%$ of the times they are operated. In a 3 -month period containing 65 weekdays, 13 Saturdays, and 13 Sundays, that would mean about 4.5 observations per scheduled weekday trip and just under 1 observation of each Saturday and Sunday scheduled trip. A 1998 survey found net recovery rates for APCs ranged from $25 \%$ to $75 \%$, with newer systems having better recovery rates (1). King County Metro, an older system, reports that its APC recovery rate has improved from $50 \%$ to the $60 \%$ to $70 \%$ range in the past year thanks to improvements in technology and logistics. STM, in addition to stringent validity tests during procurement, also uses fulfillment of APC sampling plans as a management performance indicator. Data recovery failure can be due to mechanical failure, but more often it stems from failure to match a recorded trip to the schedule or from passenger counts not balancing.

An average sampling rate can mask significant variations across the system. When fleet penetration is small, logistical difficulties coupled with the vagaries of data recovery failure often result in some scheduled trips being observed less often than expected, perhaps going completely unobserved.

In general, the sample sizes that result from $10 \%$ to $15 \%$ fleet penetration are sufficient for analyses that involve the mean or total of a 
quantity, such as total passenger miles (required for FTA National Transit Database reporting), mean boardings, and mean running time. They also are sufficient for analyses that involve considerable aggregation, such as boardings per revenue-hour (for route economic performance analysis) and stop-level demand by route, direction, and period (for service planning).

Larger and even complete fleet penetration for APCs has advantages, however, that help offset the costs. First, it provides the larger sample size needed for analyses involving variability, extreme values, and proportions. Examples are 95th percentile running time (which might be used to help determine needed recovery time), proportion of trips with load greater than capacity, and proportion of departures that are on time. The passenger count measure most in need of a large sample size is load on busy routes. A transit agency commonly faces the contradiction of load data that indicate that a route has plenty of capacity on average, yet customers complain about overloads. Tri-Met, with about $65 \%$ of its fleet instrumented with APCs, can analyze what fraction of days in each 3-month period each scheduled trip was over capacity. For decades, industry practice has been to schedule headways on busy routes based on average peak load, ignoring variability; however, this practice is really an accommodation to data scarcity. On routes with large load variability, smaller average peak loads are needed to limit overloads; on routes with little load variability, average peak load can be greater without risking much overloading.

Leader-follower or headway analysis is particularly sensitive to data recovery and fleet management practice because it requires valid observations of consecutive pairs of trips. The number of valid headways one can expect to observe is proportional to the square of the data recovery rate and the correct assignment rate. For example, if the data recovery rate is $70 \%$ and if a request to instrument a given route results in $90 \%$ of the trips on that route having an instrumented bus, one can expect to observe only $(0.7)^{2}(0.9)^{2}=40 \%$ of the day's headways on that route.

A large fleet penetration rate allows more timely analysis of datathat is, a shorter period of time is needed to accumulate the sample size needed for a given analysis. Also, with complete penetration, the significant logistical hassles over circulating instrumented buses disappear. Maintenance and political factors (e.g., spread the new buses, or put the new buses on this side of town) often determine where instrumented buses are garaged, complicating data collection. For these reasons, as well as the sampling reasons described earlier, TriMet decided a few years ago that all new bus purchases would include APC. Because their APC system shares the AVL system's location, schedule matching, and communication facilities, the marginal cost of installing APC in a bus has decreased to only $\$ 1,000$.

\section{Exception Reporting, Yes; Exception Recording, No}

Exception reporting is a valuable tool for reports and radio messages to prevent information overload. Exception radio messages can also aid dispatchers in real time by bothering them only when something needs attention. For example, Tri-Met uses three different thresholds for lateness: for signal priority, $2 \mathrm{~min}$; for historical performance reports, $5 \mathrm{~min}$; and for a "late alarm" radio message to dispatchers, $8 \mathrm{~min}$.

However, most analyses require that data be recorded on all trips, not only exceptions. Researchers at Morgan State University in Baltimore, Maryland, tried to analyze schedule deviation and running time using exception data gathered by Baltimore's 1995-vintage
AVL system, in which buses within an on-time window (1 min early to 5 min late) send back only a "status OK" message, which is not archived; the only archived timepoint records are from buses outside that window (9). The researchers had to guess the schedule deviation of buses within the on-time window. Still worse, trips that were never outside the on-time window didn't appear at all in the database, just like trips that were missing or had malfunctioning radios. The transit agency has since discontinued attempts to analyze data from that AVL system.

\section{Connections to Capture Other Data Items}

Tying an AVL or APC to other devices can create valuable data synergies. One valuable connection already mentioned is to the farebox, by means of which location-stamped fare transaction records could allow one to estimate load, reconstruct linked trips, and analyze transfers based on actual transfer rates.

\section{Making the Most of Control Communications}

In radio-integrated AVL systems, the event stream usually includes coded radio messages initiated by the operator. Useful codes for data analysis include those for pass-ups (when a waiting customer can't be picked up due to overload), fare evasion, fare dispute, or blockage at a railroad crossing or drawbridge. However, the value of such event records depends on operator compliance. For example, when Tri-Met's service analysis group analyzed fare evasion event records to show locations of high rates of fare evasion, the analysis was received with skepticism because it was generally believed that most fare evasion goes unreported.

Also of value, but not yet applied in an AVL system to the authors' knowledge, would be records of communications initiated by the control center, such as instructions to hold or detour.

\section{DATABASE DESIGN ISSUES}

\section{Integrating with Enterprise Databases}

Integrating AVL with the scheduling database has proven to be a large but surmountable obstacle for many transit agencies. Because of difficulties brokering the development of the schedule interface between the scheduling software contractor and the AVL contractor in an earlier procurement, CTA's recent procurement puts the coordination responsibility on the stop announcement contractor, who had to budget for subcontracting to the scheduling software vendor. Complicating matters for AVL vendors is the fact that scheduling databases often have custom features that hinder the transferability of an interface from one agency to another, even if both have the same schedule software.

Route and stop databases are rarely perfect because before automated data collection and analysis, they didn't have to be (2). An AVL system can be designed to help improve those databases with such features as learning mode and analysis of measures versus scheduled stop location.

\section{Data Cleansing}

In a real-time only system, bad data are often just a momentary blip that people in the control room learn to ignore. When archived, how- 
ever, bad data can interfere with many analyses (2). Because of the huge sample size afforded by automated data, a lot of data can be thrown out. Therefore, the first step in data cleansing is to throw out data that is out of range. A classic example is on-and-off counts whose totals don't agree (to a certain tolerance).

A related problem is balancing on-and-off counts. The main issue is preventing errors from accumulating. Best practice is to identify known points of zero load (layover terminals), force the load there to be zero, and make small adjustments between such points, avoiding negative loads.

One common problem that results in erroneous data in the database is the difficulty in resolving end-of-line activity. A bus in a terminal area may open its doors or move several times between ending one trip and starting the next; a system sometimes mistakes such intervening movements as arrivals and departures. For this reason, many agencies don't trust running time analysis on first and final segments of a route, limiting the usefulness of AVL data. King County Metro has improved its end-of-line matching by ignoring bus movements after arrival at terminal and more than $3 \mathrm{~min}$ before scheduled departure. Greater detail in the data stream (e.g., stop records or Level E data detail) can help eliminate many end-of-line ambiguities.

The transit agencies that have made the greatest progress with archived data show a strong ongoing commitment to improve data quality. Staff members ensure that the data are received properly; note how much data were rejected and why; look for patterns in matching failures; and develop improved algorithms for matching, editing, and analyzing the data.

\section{Analysis and Report Options}

On the basis of this survey, transit agencies want three levels of analysis and report options. At one end of the spectrum, they want flexibility to query and analyze the data in any way. Some of the larger agencies with AVL systems have skilled analysts able to do just that. At the other end of the spectrum, they want standard reports that can be run by various users without programming or database skills.

The middle option is standard procedures that may involve complex programming producing tables that can then be custom formatted using standard report-generating software. Tri-Met's service analyst follows this path: He uses a powerful statistical package to perform data selection and calculation logic, which result in large tables, then a standard database package for functions such as formatting and sorting. This two-stage method offers the possibility of standard sets of analysis procedures that might be transferred between different transit agencies.

\section{ORGANIZATIONAL ISSUES}

Effective use of automated data requires complete transformation of an organization. It is not surprising, then, that organizational issues often have hindered its development. A summary of some of the key lessons learned from these surveys follows.

\section{Improving Quality of Operator-Generated Data}

Operator-generated data can be an important part of the data stream, but their value depends on high accuracy and compliance rates. Several things can be done to improve the quality of such data.
The first is to minimize the need for operator-generated data. Rather than requiring the operator to enter a code for wheelchair lift use, many systems have a lift sensor. To minimize erroneous operator login data, Tri-Met and Metro Transit generate log-in data automatically from the results of the overnight bus assignment process; operators then only have to verify that their block numbers are correct.

NJ Transit at first designed a system that would run with no operator input at all. However, they later found that verifying that a day's service on a bus followed the block number entered by the operator turned out to be a far more efficient way of schedule matching than ignoring the operator's input.

Real-time monitoring of operator inputs, when it can be arranged, can improve data quality. For example, some systems will check that the identification entered by the operator is valid. In systems integrated with the radio, when an operator doesn't log in properly, a supervisor is likely to visit the bus (because one isn't supposed to operate without a functioning radio). For this reason, erroneous login data are rare at King County Metro, except on trippers (one- or two-run pieces of work). Enforcement based on public complaints is less effective but still better than nothing. For example, if operators are disciplined for failing to report a pass-up if a customer later complains, operator compliance in reporting pass-up events will likely improve.

\section{Avoiding Labor Opposition}

Suspicion of "the spy in the cab" or "big brother" is natural. If transit operators resent being monitored, they can sabotage the system, either physically or by otherwise rendering its data useless, especially if they believe that the system is unfair or inaccurate.

For the most part, transit agencies that have adopted AVL and APC have avoided incapacitating labor opposition. Communicating the security benefits of AVL helps build operator support. (APCs generally don't engender opposition, probably because their name suggests that they're counting only passengers.) Most agencies avoid directly challenging operators with AVL or APC data. TriMet has a formal agreement with the labor union preventing discipline on the basis of AVL data. However, they still analyze the data to identify patterns of abuse (e.g., returning late to the garage when the last trip ended on time) or poor performance (e.g., starting late, even though the previous trip ended on time) and alert supervisors as to where and when problems are likely to occur.

\section{What's the Benefit?}

Perhaps the biggest organizational obstacle is convincing management of the benefit of archived data analysis. Thus one is presented with a version of the chicken-and-egg problem: The benefits of an archived data system cannot be easily proven until it has been applied, but management won't provide the needed system features, support, and staffing unless it believes that the system's benefit will be worth its costs.

This survey suggests that the benefits of archived AVL-type data are still far from being realized at any agency. Most often, data systems are still immature. Even where data systems are producing well, the schedulers, planners, supervisors, and staff members with other functions can take a long time to adjust their practices to a data-rich environment when practices developed for a data-poor environment are well entrenched. 
Nevertheless, this survey offers plenty of information to support the concept that the benefits of archived AVL-type data will indeed be substantial. Consider the following:

- Scheduling systems prove their worth by finding efficiencies that reduce operating costs by a small fraction, often $1 \%$ or $2 \%$. Analysis of loads and running times will likely offer similar if not greater benefits, such as making decisions about needed running time, recovery time, and headway based on a large, reliable sample rather than a meager manual sample. Several transit agencies report that this area is where they find the greatest benefit of their AVL system.

- On Line 1 in Eindhoven, when extensive data analysis was combined with signal priority to make operations reliably on time, ridership increased $25 \%$. Granted, some of that increase is due to faster running times offered by signal priority (trip time reduced from 23 to $21 \mathrm{~min}$ ), and a significant part of the increase is attributed to improvements in the route's on-time performance, which could occur only with schedule adjustments based on extensive data analysis.

- Throughout the business world, measurements help improve quality; one should expect transit operations to be no different. At STM, garage managers are held accountable for the on-time performance of their divisions, enforced through APC measurements. Upper management, in establishing this program, certainly believes that garage managers can and will improve service quality if held accountable. At Tri-Met, an analysis of on-time performance by operator has revealed that much of the problem is operator specific $(10)$. This analysis compares each operator's performance to the average performance of operators on the same route, direction, and period. These data are passed on to supervisors, who can use it to target supervision and training efforts (because they cannot discipline an operator directly from AVL or APC data).

- When service is contracted out, service quality is often ensured through the use of penalties and incentives in the contract relating to specific, measurable items such as on-time performance. AVL with data archiving offers the necessary means of data collection to enforce such a provision.

- Conditional signal priority is one of the most promising means for improving transit service. However, it demands a finely tuned schedule of arrival time at every intersection, set so that about onehalf if the buses arrive early and one-half arrive late. Only automated data collection, archiving, and analysis can provide the finely tuned schedules needed to make conditional priority work.

- Transit agencies need the cooperation of traffic management authorities to improve transit speed and reliability. Archived AVL data provide the information needed to make a convincing case for and assess the impact of traffic management interventions.

\section{CONCLUSION}

The usefulness and benefit of archived data derived from an automated data collection system depend on the system's design. This paper has discussed key issues related to design of the data collection system itself and of its database as well as related organizational issues. The authors hope that this research will help guide the development of automated data collection systems.

\section{REFERENCES}

1. Furth, P. G. Synthesis of Transit Practice 34: Data Analysis for Bus Planning and Monitoring. TRB, National Research Council, Washington, D.C., 2000.

2. Kemp, J. Lessons Learned-Things You Didn't Need to Think About When It Was Just Automatic Vehicle Location. Presented at the 81st Annual Meeting of the Transportation Research Board, Washington, D.C., 2002.

3. Cevallos, F. Using dBASE to Collect AVL Data. The dBase Developer's Bulletin, Vol. 16, July 2002. www.dbase.com/Knowledgebase/ dbulletin/bu16_htm.

4. Furth, P. G., B. J. Hemily, T. H. J. Muller, and J. G. Strathman. TCRP Web Document 23: Uses of Archived AVL-APC Data to Improve Transit Performance and Management-Review and Potential. Project $\mathrm{H}-28$, Contractor Final Report. TRB, National Research Council, Washington, D.C., June 2003. gulliver.trb.org/publications/tcrp/tcrp_webdoc_23.pdf.

5. Muller, T. H. J., and P. G. Furth. Trip Time Analyzers: Key to Service Quality. In Transportation Research Record: Journal of the Transportation Research Board, No. 1760, TRB, National Research Council, Washington, D.C., 2001, pp. 10-19.

6. Navick, D. S., and P. G. Furth. Estimating Passenger Miles, OriginDestination Patterns, and Loads with Location-Stamped Farebox Data. In Transportation Research Record: Journal of the Transportation Research Board, No. 1799, TRB, National Research Council, Washington, D.C., 2002, pp. 107-113.

7. Barry, J. J., R. Newhouser, A. Rahbee, and S. Syeda. Origin and Destination Estimation in New York City with Automated Fare System Data. In Transportation Research Record: Journal of the Transportation Research Board, No. 1817, TRB, National Research Council, Washington, D.C., 2002, pp. 183-187.

8. Levine, J. Evaluation of the Advanced Operating System of the Ann Arbor Transit Authority: Transfer and On-Time Performance StudyBefore and After AOS Implementation. Intelligent Transportation Systems Office, U.S. Department of Transportation, 2000, modified 2001. www.its.dot.gov/EVAL/docs_transitmgt.htm.

9. Lee, Y.-J., K. S. Chon, D. L. Hill, and N. Desai. Effect of Automatic Vehicle Location on Schedule Adherence for Mass Transit Administration Bus System. In Transportation Research Record: Journal of the Transportation Research Board, No. 1760, TRB, National Research Council, Washington, D.C., 2001, pp. 81-90.

10. Strathman, J., K. Dueker, T. Kimpel, R. Gerhart, and S. Callas. Evaluation of Transit Operations: Data Applications of Tri-Met's Automated Bus Dispatch System. Transportation, Vol. 29, 2002, pp. 321-345.

Publication of this paper sponsored by Transit Management and Performance Committee. 